\title{
Pre-teenage Children's Vernacular Perception and Experience of Maps in Hong Kong
}

\section{Tammy Kwan}

Department of Curriculum Studies, The University of Hong Kong, Pokfulam Road, Hong Kong

This paper reports a questionnaire study conducted with a group of 87 pre-teenage children (age 11-12 years) in Hong Kong to show their vernacular perception and experience of maps before they began formal mapwork learning in their first year of secondary education. This study reveals major findings that these pre-teenage children see the main purpose of using maps is to find unfamiliar places and to locate them in most everyday situations. As a result, they like to deal with practical, real maps such as street maps and the MTR (Mass Transit Railway) transport maps where the abovementioned practical map purpose can be achieved. Most of these pre-teenage children are aware of maps available in their surroundings. However, they may not be observant enough to notice or pay attention to reading them carefully. It is rather a matter of map awareness that puts these pre-teenage children into the two broad groups of map and non-map-users. It also revealed that even those pre-teenage children who claimed to be non-map-users demonstrated some intuitive superficial understanding of simple map concepts and elements. Teachers are strongly encouraged to tap into the intuitions and experiences possessed by pre-teenage children in order to develop their map interest further in geography lessons and to make the understanding of maps a practical life skill for them to master.

\section{Introduction}

According to the findings of many researchers (Bartz, 1970; Freundschuh, 1990; Gerber; 1981, 1993; Matthews, 1984a, b, 1992; Rushdoony, 1969; Stimpson, 1987; Spencer et al., 1989; Walker, 1980; Wilson, 1980) children demonstrate the ability to conceptualise information from maps at quite an early age. Some studies reveal the difficulties faced by young children from seven to 12 years in of conceptualising map-related knowledge, though there is also evidence that it develops and progresses with age (Dale, 1971; Liben \& Downs, 1989; Satterly, 1964; Tierney, 1985). Such findings, on the other hand, are quite contradictory to what was first suggested by the Piagetian school of thought (Piaget, 1929; Piaget \& Inhelder, 1956), that children are not able to conceptualise abstract ideas, such as those embedded in maps, until they are in the stage of formal operations which is roughly from the age of 13 years.

In Hong Kong, educators and curriculum planners need to know children's ability to understand and learn maps. Generally, pre-teenage children up to the age of 11 years are not given the opportunity to learn about maps formally in their primary schools. Teachers may show pre-teenage children some illustrative maps such as those depicting major continents, political divisions within continents and related kinds of maps. These children, however, are not taught formally the way to read or draw maps. It is only when they enter secondary 
school that they have the opportunity to study maps formally through geography. By that time, they are over 12 years of age, entering adolescence and they are close to the formal operation stage as suggested by Piaget, and, according to his thesis, they should be able to begin to conceptualise more abstract ideas, including those found on maps.

Nevertheless, geography teachers in Hong Kong find it difficult to teach maps to the junior Secondary $1^{1}$ pupils (12+ years) who do not yet possess formal map-learning experience and hence show no interest in using and studying maps in geography lessons. Even if some of the students do show an interest in maps, they have problems in mastering the skills of learning and understanding them (Kwan, 1994). However, if one refers to the research findings mentioned earlier, one should not be so pessimistic. Very young children in some cultures have demonstrated the ability to read or use maps to some extent (Boardman, 1989; Gerber, 1982). In other words, they read and use maps without necessarily have gone through the processes of formal instruction. To what extent, then, do pre-teenage children in Hong Kong see maps, understand maps, prefer maps, use maps and, perhaps, experience maps? In most advanced cultures, they will have come across maps before they begin formal map learning in secondary schools. How may these 'pre-school' map experiences help them to self-conceptualise maps? If such 'prior' information about children's ability to understand and experience maps could be made available, it might help geography teachers to plan their teaching about maps more effectively and with more appeal to these pre-teenage children when they begin formal map learning.

\section{The Study: Purposes, Subjects of Study and Questionnaire Exercise}

This paper reports a questionnaire exercise, which was implemented with two classes of Secondary One pre-teenage children (age 11-12 years), comprising a total of 87 children, from two urban schools with 'new middle class' family background. ${ }^{2}$ The children's academic standard is regarded as average in these two schools. The questionnaire exercise was conducted in the first week of a new academic year in the two urban Hong Kong schools. The timing was of critical importance to the purpose of this study. In Hong Kong, pre-teenage children of age 11-12 years have just completed their final year of primary education, a period in which they do not receive any formal instruction in mapwork. It is only when they begin their secondary education that formal lessons on maps and mapwork are introduced through geography.

The purposes of this study, therefore, were to explore and to illuminate: (1) how much pre-teenage children in Hong Kong know about maps before they begin formal mapwork learning in their first year of secondary education, and (2) their experience with maps before they formally encounter map learning and lessons in school.

The 87 pre-teenage children of two Secondary One classes from two Hong Kong urban schools were asked by their teachers to complete a six-page questionnaire exercise (written in Cantonese) designed to find out their 'intuitive' map understanding and their map experience (Kwan, 1996). Since this was regarded as a qualitative exploratory study which is contextually based to reveal a 'black-box' phenomenon, i.e. the pre-teenage children's understanding and 
experience of maps before they formally encounter map learning and lessons in secondary school, there was no need to engage in the precise sampling of schools and children that is normally expected in an experimental study design.

The six-page questionnaire exercise consisted of five key questions which further broke down to 15 subquestions (see Appendix 1) on both textual and graphical media of map information. The five key questions were:

(1) How much do pre-teenage children experience about maps before formal mapwork begins?

(2) What do pre-teenage children understand maps to be?

(3) What are the pre-teenage children's perceptions on the purposes of maps?

(4) How many different types of map do pre-teenage children know?

(5) What are the pre-teenage children's personal experiences with maps?

For most of the questions, the pre-teenage children were asked to tick the option, which most appropriately described or reflected their intuitive understanding and experience of maps. They were also invited to write brief comments on what they thought about a particular map and its associated elements. The intention was to gather as much complementary descriptive information about the pre-teenage children's ways of using, understanding, perceiving, preferring and experiencing maps as possible.

Despite the provision of explicit written and verbal instructions, some pre-teenage children still ticked more than one option in some of the questions. Nevertheless, the total number of ticks for every option was tallied and a simple percentage was calculated to reveal the relative importance of each option in the question. Hence, the information on the understanding of maps in the two classes of pre-teenage children before receiving any formal teaching is regarded as relative rather than absolute. In fact, quite a number of the pre-teenage children surprisingly wrote down reasonably detailed descriptions on individual options. An initial impression was then obtained that if pre-teenage children were given the chance to write and talk about what they thought of certain ideas or topics, they would have a lot to communicate to their teachers.

The two participating schools were located in the same 'geographical constituency' drawing students from similar socioeconomic backgrounds. The two classes were recommended to the researcher by the teachers, with the approval of the principals, based on the students' screening entrance test, which indicated that they were of an average academic standard for Hong Kong. All the pre-teenage children were within the age range of 11-12 years. The sample comprised of 64 girls and 23 boys. Although more girls than boys participated in this questionnaire exercise, it is not the intention of this study to compare responses of pre-teenage children of different gender and with different academic abilities. The study was conducted to find out how children of that age range, not yet having encountered any formal teaching about maps in their primary schools, understood, perceived and experienced maps.

The questionnaire exercise was administered by the researcher, in the presence of the class teacher, in the second geography lesson of the new academic term in September. The researcher read each question to the class and elaborated its meaning to ensure that all the pre-teenage children fully understood it. The 
researcher waited until all the children in the class had finished one question before proceeding to read the next one. The presence of the class teacher was required as he/she could help with elaborating any question to an individual student who required additional assistance. However, such elaboration was confined only to repeating what had already been said by the researcher to the particular student who needed such assistance. The teacher's presence was also of assistance in preparing subsequent map lesson teaching based on what had been observed about the children's responses to the exercise. The whole six-page questionnaire, containing five parts and 15 subquestions, was completed in 40 minutes.

\section{Findings and Discussions}

This section reports the findings of the pre-teenage children's responses to the questionnaire exercise according to the five key questions listed above. The focus of discussion is on direct exposure of what these children think about maps and how they have experienced maps before formal map learning begins. Their understanding, preference and perception of maps are qualitatively revealed simply through the use of descriptive percentages and appropriate inclusion of written comments as they were recorded in the questionnaire exercise. There is no intention to engage in statistical testing relating to any hypotheses.

\section{How much do pre-teenage children experience about maps before formal mapwork begins?}

\section{Have the pre-teenage children used maps before?}

Of the 87 pre-teenage children (64 girls and 23 boys), 21 (24\%) of them said that they had never used maps before and 66 (76\%) claimed that they had used maps before. The first group of pre-teenage children is referred to as non-map-users and the second group as map-users in the rest of this paper. Table 1 summarises the gender distribution of the 87 children in using maps before their formal learning take place.

Table 1 Gender distribution of the pre-teenage children in using maps before their formal map learning begin in school $(N=87)$

\begin{tabular}{|l|c|c|c|c|c|c|}
\hline \multirow{2}{*}{ Pre-teenage children } & \multicolumn{2}{|c|}{ Girls } & \multicolumn{2}{c|}{ Boys } & \multicolumn{2}{c|}{ Total } \\
\cline { 2 - 7 } & Number & $\%$ & Number & $\%$ & Number & $\%$ \\
\hline Non-map-users & 19 & 30 & 2 & 9 & 21 & 24 \\
\hline Map-users & 45 & 70 & 21 & 91 & 66 & 76 \\
\hline Total & 64 & 100 & 23 & 100 & 87 & 100 \\
\hline
\end{tabular}

There were more girls than boys in the study purely according to the two classes nominated to engage in this questionnaire exercise. Though it is not the intention of this study to compare gender difference in map understanding and experience, the children in this group of study revealed more girls (30\%) claiming themselves as non-map-users than boys (only 9\%). This seems to indicate comparable findings with Matthews (1986) and Bramwell (1987). They concluded that boys tend to exhibit a higher ability to explore their nearby spatial 
environment because they are allowed to be on their own while girls are not normally allowed to stay very far out of their home area for long by themselves. If the pre-teenage children have used maps before, what did they use maps for?

The 66 pre-teenage children referred to as map-users nominated three conditions under which they would have used maps. The three conditions are: (1) to find the ways around so that they know how to get from one place to another $(28 \%)$, (2) to find out more about unfamiliar places (31\%), and (3) to locate places $(30 \%)$. This first condition of use is regarded as different from just finding familiar or unfamiliar places on a map as it reflects the practical intention of using maps to fulfil a purpose, i.e. to find out how to get to a place. The latter two conditions (accounting for a total of $61 \%$ ), however, occur more out of curiosity. For instance, the children may just look up a map to know where a place, such as a country or a city, is. These findings are summarised in Table 2.

Table 2 The purposes of the map-user pre-teenage children in using maps

\begin{tabular}{|l|c|c|}
\hline $\begin{array}{l}\text { What did the map-user pre- } \\
\text { teenage children use map for? }\end{array}$ & Number & $\%$ \\
\hline For fun & 6 & 5 \\
\hline No particular purpose & 6 & 5 \\
\hline To find ways around & 33 & 28 \\
\hline To locate places & 35 & 30 \\
\hline To find unfamiliar places & 36 & 31 \\
\hline Others & 2 & 1 \\
\hline
\end{tabular}

The percentage distribution in Table 2 reveals that many pre-teenage children have had hands-on experience of using maps to find places and various locations before they study mapwork in geography. Findings from subsequent items also confirm that practical use of maps often happens in the pre-teenage children's daily lives before they encounter mapwork in school. This finding should guide teachers to consider seriously the use of real maps in classroom teaching and learning. At present, most Hong Kong teachers still use hypothetical simplified maps to introduce abstract map concepts (Kwan, 1994; Stimpson, 1987) to pre-teenage children. This makes map learning unreal to them.

\section{What do pre-teenage children understand maps to be?}

\section{Which graphic is a map? Why do the pre-teenage children think it is a map?}

The pre-teenage children were asked to distinguish a map from a sketch, an oblique drawing and a plan of a classroom (see Figure 1), and to suggest what kind of elements should be included to make a particular drawing a map. The intention was to check the criteria used by the pre-teenage children to reflect their map understanding.

Figure 1, containing three graphics, was shown to the pre-teenage children so that they could state which one was a map and give reasons for their choice. Eighty-five $(97.7 \%)$ of the pre-teenage children chose Figure $1 \mathrm{~b}$ as their answer. 

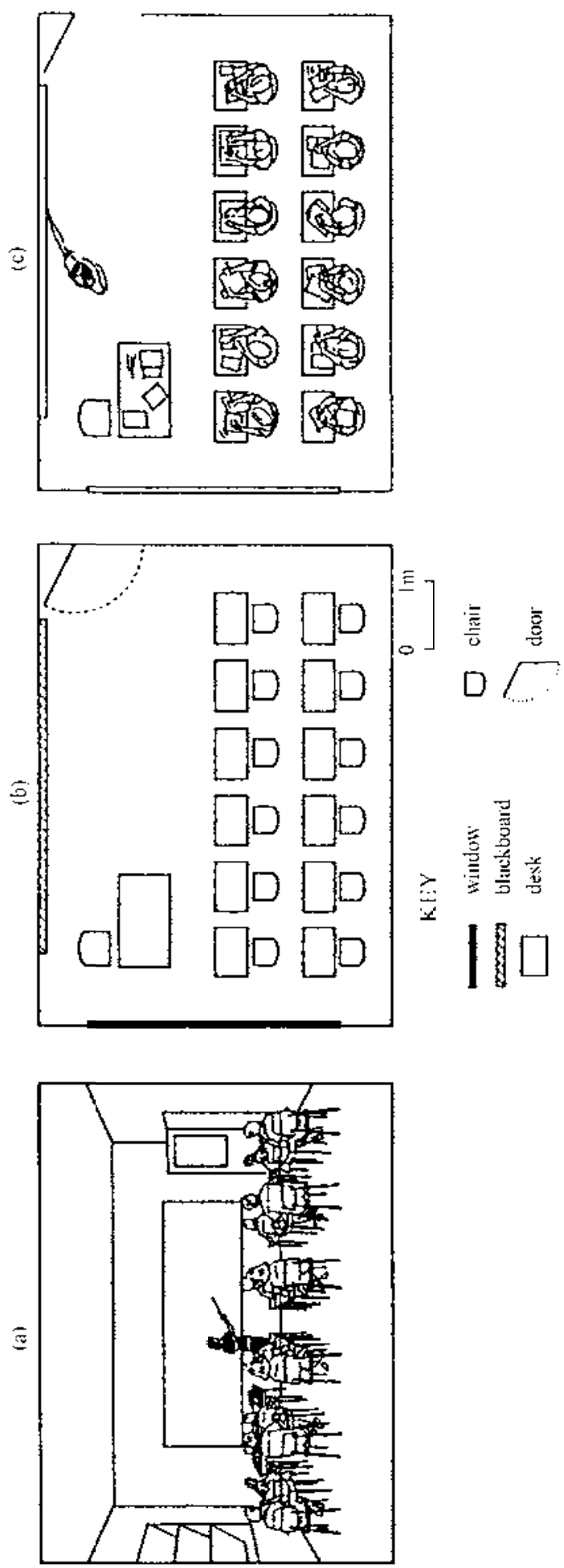
The written comments revealed that they consider symbolic representation as one of the important elements of a map. A few of them also considered scale, dimensional view, and absence of people, to determine whether a particular graphic is a map. The following written expressions illustrate these conclusions:

- Consideration of symbolic representation, e.g. key.

'b" has a key.'

'In " $b$ ", all furniture is represented by symbols.'

" $\mathrm{b}$ " is a map because it states clearly that every thing is represented by a symbol.'

'"b" contains a clear key for explanation.'

- The absence of people.

'Because the emphasis of " $b$ " is not on people but on the drawing of desks' positions.'

'A map does not need people on it.'

'" $\mathrm{b}$ " is drawn as a plan map because there is [sic] no people in it.'

- The idea of scale.

'"b" has a metered ruler.'

't also has a scale to tell the real distance.'

- Others.

'Because this map " $b$ " simply tells us where we want to find the places.' '"b" is a plan and a map as well because it is looked down from above.'

What are the things (items) that need to be included on a map?

This question asked the pre-teenage children to consider a list of 12 items that they thought should be included on a map. The pre-teenage children were permitted to tick as many of these items as they wished. This list of 12 items was divided into three categories of technical, everyday and symbolic representations of common map elements and included:

- four technical representations of map items such as 'scale', 'key', 'north point', and 'map title';

- four common representations or expressions of the above four technical items, such as 'lines', 'symbols', 'arrow', and 'words'; and

- four symbolic representations or expressions of the four technical items, such as 'numbers', 'colours', 'squares' and 'place names'.

Altogether, 653 ticks were recorded. On average, each pupil considered that 7.5 items out of the 12 items should be included on a map. For non-map-users, the average was 6.25 items and for the map-users 8.12 items. Both groups regarded 'place names', and 'a north point' as the most important items on a map; and 'arrow - a common representation of the north point', 'numbers - which commonly appear on a scale or grid line' and 'squares - are the common crossing of northing and southing lines to form the grid' as the least important items. However, there was some difference in preferences towards two items, namely, 'scale' and 'words'. Although both map-users and non-map-users had similar percentage counts towards 'scale', the non-map-users opted for it more often than the map-users. With regard to 'words', which are normally used to represent place names and map title, these were rated highly $(79 \%)$ by the map-users while 
Table 3 Items that pre-teenage children think should be included on a map $(N=87)$

\begin{tabular}{|l|c|c|c|c|c|c|c|c|c|}
\hline \multirow{2}{*}{ Items } & \multicolumn{3}{|c|}{ Map-users (66) } & \multicolumn{3}{c|}{ Non-map-users (21) } & \multicolumn{3}{c|}{ Total (87) } \\
\cline { 2 - 11 } & No. & $\%$ & Rank & No. & $\%$ & Rank & No. & $\%$ & Rank \\
\hline Scale & 46 & 70 & 7 & 15 & 71 & 3 & 61 & 70 & 5.5 \\
\hline Key & 31 & 47 & 9 & 9 & 43 & 7 & 40 & 46 & 9 \\
\hline N-Point & 63 & 95 & 2 & 18 & 86 & 2 & 81 & 93 & 2 \\
\hline Map Title & 41 & 62 & 8 & 8 & 38 & 8 & 49 & 56 & 8 \\
\hline Lines & 47 & 71 & 6 & 14 & 67 & 4 & 61 & 70 & 5.5 \\
\hline Symbols & 55 & 80 & 3 & 12 & 57 & 5 & 65 & 75 & 3 \\
\hline Arrow & 29 & 44 & 10 & 7 & 33 & 9.5 & 36 & 41 & 10 \\
\hline Words & 52 & 79 & 4.5 & 7 & 33 & 9.5 & 59 & 68 & 7 \\
\hline Numbers & 23 & 35 & 12 & 5 & 24 & 11 & 28 & 32 & 12 \\
\hline Colours & 52 & 79 & 4.5 & 10 & 48 & 6 & 62 & 71 & 4 \\
\hline Squares & 29 & 44 & 10 & 0 & 0 & 12 & 29 & 33 & 11 \\
\hline Place names & 65 & 98 & 1 & 20 & 95 & 1 & 85 & 98 & 1 \\
\hline Total & 528 & & & 125 & & & 653 & & \\
\hline Average items & \multicolumn{3}{|c|}{8.12 items } & \multicolumn{7}{|c|}{6.25 items } & & 7.5 items \\
\hline
\end{tabular}

only $33 \%$ of the non-map-users agreed that 'words' should be included on a map. This contradicted their top preference of 'place names' since they can only be represented in words on a map. There seems to be no immediate justification to explain such differences and contradictions between the groups. It does, however, indicate that pre-teenage children from either group, whether they claimed themselves to be map-users or non-map-users, were somewhat confused with regard to which elements should be included on a map. Though they had some ideas of what maps are and their usage, they are not familiar with what exactly should constitute a map with regard to the basic map elements, indicating a necessity for teachers to clarify this part with the students when map lessons begin in secondary school.

\section{Which things (items) on a map do pre-teenage children believe they know the meanings of?}

It is understood that while pre-teenage children may tick a particular item to be included on a map because they have heard about it before, they may not have understood the meaning of that item. Hence, this question was set to ensure the pre-teenage children understood, or at least believed that they understood, what they had ticked in the above question. The result showed that there were fewer ticks for this question, indicating that the pre-teenage children were not clear why some items have to be included on a map. In general, all the pre-teenage children thought that they were sure of the meaning of an average of 6.15 items used on a map. This, when compared with the 7.5 items that they considered should be included on a map, showed that they had an average of 1.35 items (i.e. 7.5 items minus 6.15 items) of meaning unclear on a map. The map-users exhibited a similar figure of 1.49 items (i.e. 8.12 items minus 6.63 items) of unclear meaning, whereas the non-map-users exhibited a higher figure of 1.9 items (i.e. 6.25 items minus 4.35 items) of unclear meaning.

In terms of the ranking of the items, there was a similarity in performance for 
Table 4 Items used on a map whose meaning pre-teenage children are sure $(N=80$, with 7 non-respondents)

\begin{tabular}{|c|c|c|c|c|c|c|c|c|c|}
\hline \multirow[t]{2}{*}{ Items } & \multicolumn{3}{|c|}{ Map-users (63) } & \multicolumn{3}{|c|}{ Non-map-users (17) } & \multicolumn{3}{|c|}{ Total (80) } \\
\hline & No. & $\%$ & Rank & No. & $\%$ & Rank & No. & $\%$ & Rank \\
\hline Scale & 43 & 68 & 3 & 9 & 53 & 3 & 52 & 65 & 3 \\
\hline Key & 21 & 33 & 10 & 6 & 35 & 5 & 27 & 34 & 10 \\
\hline N-Point & 57 & 90 & 2 & 11 & 65 & 2 & 68 & 85 & 2 \\
\hline Map title & 32 & 51 & 7.5 & 4 & 24 & 9.5 & 36 & 45 & 8 \\
\hline Lines & 32 & 51 & 7.5 & 5 & 29 & 7.5 & 37 & 46 & 7 \\
\hline Symbols & 34 & 54 & 6 & 5 & 29 & 7.5 & 39 & 49 & 6 \\
\hline Arrow & 26 & 41 & 9 & 4 & 24 & 9.5 & 30 & 37 & 9 \\
\hline Words & 42 & 67 & 4 & 6 & 35 & 5 & 48 & 60 & 4 \\
\hline Numbers & 17 & 27 & 11 & 1 & 6 & 11.5 & 18 & 22 & 11 \\
\hline Colours & 40 & 63 & 5 & 6 & 35 & 5 & 46 & 57 & 5 \\
\hline Squares & 12 & 19 & 12 & 1 & 6 & 11.5 & 13 & 16 & 12 \\
\hline Place names & 62 & 98 & 1 & 16 & 94 & 1 & 78 & 97 & 1 \\
\hline Total & 418 & & & 74 & & & 492 & & \\
\hline Average items & \multicolumn{3}{|c|}{6.63 items } & \multicolumn{3}{|c|}{4.35 items } & \multicolumn{3}{|c|}{6.15 items } \\
\hline
\end{tabular}

both map-user and non-map-user groups, except for the 'key', which has a rank difference of five between the two groups. If Tables 3 and 4 are examined together, it is clear that the pre-teenage children were more inclined to textual meanings on a map in the form of 'place names', 'words' and 'north point'. These map items represent concrete meanings and hence are more readily internalised by the younger children. This agrees with the findings in Table 2 that the maps that the children had used before were mainly for knowing unfamiliar places and locating places. If this is the case, it is natural for pre-teenage children to prefer 'word labels' in the form of place names and street names to help them to look up unfamiliar places. Although the pre-teenage children regarded symbolic information as one of the determinants of a map, the recognition or utilisation of such information occurs at a much later stage in their development if there is the coexistence of both textual and symbolic information (Kwan, 1996). This is particularly true when the symbols represented are referred to as its designation (Keates, 1982). By being represented as a symbol on a map, the mapped phenomenon is then assigned to a conceptual category which involves more complicated information processing by pre-teenage children at 11-12 years old (Burden, 1987; Ottosson, 1987).

\section{What are the pre-teenage children's perceptions on the purposes of maps?}

Ranking of map purposes

Five map purposes were listed in this question (Gerber, 1981; Kwan, 1994; Tierney, 1985). They were:

- for daily life application;

- as a tool to study other related subjects;

- for training a three-dimensional mind; 
- to give an overview of the ground condition; and

- to enhance spatial communication.

The pre-teenage children were asked to rank the five map purposes in descending order according to their relative importance. Table 5 summarises how the pre-teenage children had considered the relative importance of these five map purposes.

Table 5 Pre-teenage children's beliefs on the relative importance of map purposes

\begin{tabular}{|l|c|c|c|c|c|c|}
\hline \multirow{2}{*}{ Map purposes } & \multicolumn{2}{|c|}{ Map-users } & \multicolumn{2}{c|}{ Non-map-users } & \multicolumn{2}{c|}{ Total } \\
\cline { 2 - 7 } & $\begin{array}{l}\text { Weighted } \\
\text { number }\end{array}$ & Rank & $\begin{array}{c}\text { Weighted } \\
\text { number }\end{array}$ & Rank & $\begin{array}{c}\text { Weighted } \\
\text { number }\end{array}$ & Rank \\
\hline Daily life application & 142 & 1 & 51 & 2 & 193 & 1 \\
\hline Tool to study other subjects & 171 & 3 & 58 & 3 & 229 & 3 \\
\hline $\begin{array}{l}\text { Training 3-dimensional } \\
\text { mind }\end{array}$ & 235 & 4 & 60 & 4 & 295 & 4 \\
\hline $\begin{array}{l}\text { Give overview of things on } \\
\text { the ground surface }\end{array}$ & 153 & 2 & 46 & 1 & 199 & 2 \\
\hline Spatial communication & 247 & 5 & 71 & 5 & 318 & 5 \\
\hline
\end{tabular}

The findings of Table 5 show that there is not much difference between the map-user and the non-map-user groups' responses except for the two most important map purposes. The map-user group considered that maps are primarily used in daily life situations, while the non-map-user group considered that maps give an overview of things on the actual ground surface. Despite not having any formal lessons on maps, the map-using experience of the map-users was accumulated through their daily living, such as finding exits in the Mass Transit Railway system and finding ways and places in the countryside when they were having picnics or going hiking. They saw the purpose of using maps as being help them find their way in daily life. Undoubtedly, the majority of the pre-teenage children have difficulties in the conceptual and textual understanding of the two map purposes related to three-dimensional mind and spatial communication. Their apparent abstraction in meaning, which causes interpretation difficulty, put them as the lowest preferred map purposes on the list.

\section{How many different types of maps do pre-teenage children know?}

There are many different types of maps mentioned by Balchin (1985), Bartlett and Cox (1982) and Wilson (1980). Gerber (1993) states that children are exposed to a range of media in their lives. While the children use textbooks containing maps and atlases, they may also read newspapers containing a smattering of maps, and television is the medium that has the greatest impact on them. With that in mind, and also based on the researcher's teaching experience in Hong Kong, five maps of different types that would commonly be encountered by children of this age (years 10-11) in their social environment were shown to the children for comments.

\section{What are the different types of maps?}

Five different types of maps were shown to the pre-teenage children to study. 
They were: a street map showing the Hong Kong Central Business District (CBD) near the waterfront area; a pictorial map of a hypothetical Fun Park; a map showing the Hong Kong Mass Transit Railway (MTR) stations; a plan of a school; and a map showing weather information for South East Asia. These five maps were selected in the belief that pre-teenage children of ages 11-12 years may encounter these maps in their daily lives. Other more sophisticated maps, such as topographical maps and orthophoto maps, were not included. The pre-teenage children were asked to describe in one or two sentences the kind of map information contained in each map. Nearly all pre-teenage children of the map-user and non-map-user groups (95.4\%) could identify the five types of maps and were able to describe the particular map information that each conveyed. It is interesting to note that six of the pre-teenage children belonging to the map-user group did not regard the weather chart as a map. The reason they gave was that the weather chart is to supply information weather in different cities, but not to tell where the places or cities are. So, in a way, these six pre-teenage children from the map-user group possessed a very specific map purpose in their mind, which is place location. This phenomenon matches the findings of Table 2 that pre-teenage children think that maps are mainly used for finding places, both familiar and unfamiliar. They, therefore, did not consider the supply of weather information of the various cities in South East Asia, as a true map.

\section{What kind of map do pre-teenage children think they might and might not use most often?}

With reference to the five maps mentioned above, the pre-teenage children were asked to choose the one map that they thought they might use most often and one map that they might prefer not to use. They were asked to give reasons to support their preferences. The results in Table 6 indicate that both map-users and non-map-users had similar preferences concerning the maps they would like to use. The street map was the most preferred one $(43.7 \%)$ followed by the MTR transport map (36.8\%) while the school plan (12.6\%) and the pictorial map (5.7\%) were least preferred by both groups. Only one map-using pre-teenage child said he/she found the weather chart useful because it appears on the television's news and weather forecast every evening.

Table 6 The preference of pre-teenage children in using a particular type of map $(N=87)$

\begin{tabular}{|l|c|c|c|c|c|c||}
\hline \multirow{2}{*}{ Types of maps } & \multicolumn{2}{|c|}{ Map-users } & \multicolumn{2}{c||}{ Non-map-users } & \multicolumn{2}{c||}{ Total } \\
\cline { 2 - 7 } & No. & $\%$ & No. & $\%$ & No. & $\%$ \\
\hline Street map & 28 & 42.4 & 10 & 47.6 & 38 & 43.7 \\
\hline Hypothetical pictorial map & 4 & 6.0 & 1 & 4.8 & 5 & 5.7 \\
\hline MTR tube map & 24 & 36.4 & 8 & 38.1 & 32 & 36.8 \\
\hline School plan & 9 & 13.6 & 2 & 9.5 & 11 & 12.6 \\
\hline Weather chart & 1 & 1.5 & 0 & 0 & 1 & 1.1 \\
\hline Total & 66 & 100 & 21 & 100 & 87 & 100 \\
\hline
\end{tabular}


The reasons given by both groups were similar. In terms of the preferred maps, the reasons related to: (1) the concern about the amount of information that they could obtain from the map; (2) their familiarity with the place; and (3) the frequency of use. Hence, by using or reading the street maps, especially maps of less familiar places, the pre-teenage children said they could obtain a lot of information such as:

- the surrounding area;

- the name, direction, size, shape and characteristics of places and street names; and

- the distance between objects, such as buildings and special landmarks.

The MTR transport map came second on their preferred list because many of them said they used it very often (almost daily) and they had to read the map to make sure at which station to get off. Some of the comments written by the pre-teenage children included:

'If I have to go to an unfamiliar street, I need to refer to a street map.'

'I use a street map because I know I won't get lost.'

'I go to school by the MTR. I use it everyday.'

Pre-teenage children, in general, thought that they would not often use the school plan and the pictorial fun park plan. The reasons were: (1) they knew the place, such as the school, too well and therefore there was no need to use a school plan; and (2) if the map drawn looked too complicated and was congested with symbolic information, they would avoid using it.

Here, the pre-teenage children seemed to be contradicting themselves by, on the one hand, expressing a preference for a map that could provide a lot of information about places, but, on the other hand, rejecting the information-rich pictorial map. A closer look at this confirmed their preferred choice toward textual map information rather than the symbolic map information (see Tables 3 and 4). Despite having recorded earlier that they preferred maps which could provide them with lots of information about an unfamiliar area, they meant map information in textual form rather than in symbolic or pictorial form. They preferred real maps rather than hypothetical maps. To them, textual information in the form of words and names of a real place were concrete and they could make sense of them, while symbolic and pictorial information was abstract and often required decoding for meaning. It is probably their lack of experience and training in such a decoding process, that pushed the pre-teenage children away from choosing or using the pictorial symbolic map despite the fact that they knew it was information rich. Some of the comments written by the pre-teenage children included were:

'I know the school too well. I know all the rooms in the school. There is no need to use a map to find my way. They are all in my head.'

'The school will not change and hence there is no need to look at a map.'

'I don't use school map because the school area is small. I am too familiar with the room distribution. There is no need to use a map.'

'It (the information) is too crowed on the map. So many drawings. It is not a real park. So the map is not real.' 
The pre-teenage children's written comments indicate that they would like to work with real maps that provide them with useful spatial information (such as street patterns) presented in textual form (such as street names) but not so much with unreal maps (such as hypothetical maps) that contain a lot of symbolic information. They must see the need and understand the purpose of using maps and hence the maps they most liked to use had to be real and practical rather than imaginative and hypothetical. Though this finding may appear obvious to many readers, it is revealed that teachers in Hong Kong (Kwan, 1994) still ignore this and many of them still use abstract and hypothetical maps in their first lessons of map teaching in geography. As a result, many children simply lost interest in following the map teaching further despite having demonstrated their ability to understand some practical, real maps before they began their map lessons in secondary school.

\section{What are the pre-teenage children's personal experiences with maps?}

Teachers in Hong Kong often assume pre-teenage children have no idea of what maps are before they come to their secondary schools (Kwan, 1994). This study is based on the supposition that children aged 11-12 years, though they have not learned the sophisticated map concepts and skills in class, have already obtained useful personal experience with maps. It follows that teachers build on what the pre-teenage children have already acquired and should utilise such vernacular map experience, which was developed before formal map lessons begin, to enhance the understanding of the abstract and sophisticated map concepts and practise the related map skills. Indeed, the findings below reveal quite a fascinating picture about the pre-teenage children's pre-school map experiences.

\section{How often did pre-teenage children encounter maps?}

Table 7 shows the frequency of the pre-teenage children's encountering of maps. It is clear that the map-user group claimed to have encountered maps more frequently than the non-map-user group despite all of them having an equal opportunity to encounter maps in their surroundings. It is rather a matter of noticing, or being aware of, the existence of these maps (such as the MTR transport map poster in the MTR station) in their surrounding world. Map-users possibly were more aware of or sensitive to such existence and hence claimed that they had encountered maps more often daily, weekly and monthly. Teachers should pay more attention to this aspect and should try to incorporate maps encountered often in daily life into the mapwork or geography lessons to stimulate the children to get into a habit of using and reading these maps more readily.

\section{How often did pre-teenage children use maps?}

Encountering maps does not guarantee using maps. Table 8 shows the actual frequency of using maps by the pre-teenage children. There is an obvious decrease in percentages of the daily and weekly situations between Tables 7 and 8 among the map-user groups while the decrease in percentage is even more marked in the non-map-user group. It should be noted that despite 21 pre-teenage children identifying themselves as non-map-users (see Table 1), 
Table 7 Frequency of encountering maps by the pre-teenage children $(N=87)$

\begin{tabular}{|l|c|c|c|c|c|c|}
\hline \multirow{2}{*}{$\begin{array}{l}\text { Frequency of encountering } \\
\text { map }\end{array}$} & \multicolumn{2}{|c|}{ Map-users } & \multicolumn{2}{c|}{ Non-map-users } & \multicolumn{2}{c|}{ Total } \\
\cline { 2 - 7 } & No. & $\%$ & No. & $\%$ & No. & $\%$ \\
\hline Daily & 7 & 11 & 0 & 0 & 7 & 8 \\
\hline Weekly & 13 & 20 & 4 & 19 & 17 & 20 \\
\hline Monthly & 14 & 21 & 2 & 9.5 & 16 & 18 \\
\hline Odd times & 32 & 48 & 13 & 62 & 45 & 52 \\
\hline Never & 0 & 0 & 2 & 9.5 & 2 & 2 \\
\hline Total & 66 & 100 & 21 & 100 & 87 & 100 \\
\hline
\end{tabular}

fifteen of them still thought that they might use maps at odd times while two of them thought they probably would have used a map once a month. Nevertheless, the message is clear here that only 14 pre-teenage children of the map-user group had the experience of using maps on a regular basis, that is either daily or weekly. We can speculate that these pre-teenage children used maps in a practical way. Teachers should let their pre-teenage children see the relevance in using maps, particularly, in daily life situations. It is pointless to drill pre-teenage children to practise basic map concepts and map skills on hypothetical maps. Teachers should use real maps, for instance, maps of the pre-teenage children's home and school districts, which enable them to make meaning out of the maps even though they may never have come across those abstract and technical map concepts before (Kwan, 1995). The linkage and association of abstract map concepts with familiar environmental information (Spencer et al., 1989) help them to understand abstract and sophisticated map ideas. Such linkage also enables the pre-teenage children to develop meanings in the map concepts more easily and hence to use maps more readily.

Table 8 Frequency of using maps by the pre-teenage children $(N=87)$

\begin{tabular}{|l|c|c|c|c|c|c|}
\hline \multirow{2}{*}{ Frequency of using map } & \multicolumn{2}{|c|}{ Map-users } & \multicolumn{2}{c|}{ Non-map-users } & \multicolumn{2}{c|}{ Total } \\
\cline { 2 - 7 } & No. & $\%$ & No. & $\%$ & No. & $\%$ \\
\hline Daily & 3 & 4.5 & 0 & 0 & 3 & 3.5 \\
\hline Weekly & 11 & 16.7 & 0 & 0 & 11 & 12.6 \\
\hline Monthly & 14 & 21.2 & 2 & 9.5 & 16 & 18.4 \\
\hline Odd times & 38 & 57.6 & 15 & 71.5 & 53 & 60.9 \\
\hline Never & 0 & 0 & 4 & 19 & 4 & 4.6 \\
\hline Total & 66 & 100 & 21 & 100 & 87 & 100 \\
\hline
\end{tabular}

\section{Where did pre-teenage children use maps most often?}

After asking the pre-teenage children how often they encountered and used maps, it was then logical to find out where they read or used maps most often. Five suggestions were listed for the pre-teenage children to choose and rank order. These suggestions are places that pre-teenage children have commonly encountered, namely: at home, at school, in the MTR station, in the shopping centre, outdoor area and other suggestions. When they were asked to rank where 
they had used maps most often, it was interesting to note that even the non-map-users came up with identical ranking with the map-users despite the fact that they claimed earlier that they had never used maps (see Table 1). This is probably another piece of evidence to support the speculation that all pre-teenage children must have come across maps in one way or another. Those who claimed themselves to be non-map-users probably did so because they were not as sensitive towards the maps around them when compared with the pre-teenage children in the map-user group. Hence, they did not regard themselves as map-users. But when asked where they had used maps, they still came up with their suggested ranking list. Perhaps even more surprisingly, the lists given by the two groups were identical in that they both used maps more often in outdoor areas. Thus, they were in fact all map-users to some extent. This certainly should raise teachers' awareness and consideration in planning how to teach map lessons to children for the first time in their school life. Tables $9 \mathrm{a}$ and $9 \mathrm{~b}$ show the rank preference and the further breakdown of the 'other' items.

Table 9a Places where pre-teenage children used maps most often

\begin{tabular}{|l|c|c|c|c|c|c||}
\hline \hline \multirow{2}{*}{$\begin{array}{l}\text { Places where pre-teenage } \\
\text { children used maps }\end{array}$} & \multicolumn{2}{|c|}{ Map-users } & \multicolumn{2}{c|}{ Non-map-users } & \multicolumn{2}{c||}{ Total } \\
\cline { 2 - 7 } & $\begin{array}{c}\text { Weighted } \\
\text { number }\end{array}$ & Rank & $\begin{array}{c}\text { Weighted } \\
\text { number }\end{array}$ & Rank & $\begin{array}{c}\text { Weighted } \\
\text { number }\end{array}$ & Rank \\
\hline At home & 268 & 5 & 92 & 5 & 360 & 5 \\
\hline At school & 208 & 4 & 67 & 4 & 275 & 4 \\
\hline In the MTR station & 130 & 2 & 46 & 2 & 176 & 2 \\
\hline In shopping centre & 191 & 3 & 55 & 3 & 246 & 3 \\
\hline Outdoor area & 122 & 1 & 40 & 1 & 162 & 1 \\
\hline Others & 97 & & 15 & & 112 & \\
\hline
\end{tabular}

Table 9b Breaking down of the 'Others' item in Table 9a

\begin{tabular}{|l|c|c|}
\hline Pre-teenage children's suggested other items & Map-users & Non-map- users \\
\hline Weather chart & 35 & 5 \\
\hline Playground & 31 & 1 \\
\hline Overseas tour & 30 & 4 \\
\hline Miscellaneous & 1 & 5 \\
\hline Total & 97 & 15 \\
\hline
\end{tabular}

The rank order suggested by the pre-teenage children was converted into weighting numbers and items receiving the smallest score were ranked highest, representing a popular place for pre-teenage children to use maps. It is interesting to see that these pre-teenage children used maps more often in outdoor areas, which included the shopping centres and the MTR stations. This again supported the claim of popular use of maps in daily life, especially, in outdoor areas. Ironically, these pre-teenage children did not consider school a popular place to use maps. Probably this could be explained by the fact that these children did not 
have much chance to use and read maps in primary schools because they still had not started their map lessons formally.

\section{Why did pre-teenage children use maps?}

Having explored the places where pre-teenage children used maps most often, they were asked why they used maps in these locations. This question was different from the one that was asked earlier in Table 2. In Table 2, pre-teenage children were asked what they thought of the reasons for using maps in general. But this question was asked with the intention of exploring the pre-teenage children's personal experience of why they used maps with reference to their own preferred places. Table 10 summarises the reasons for using maps by the two groups.

Table 10 Reasons for pre-teenage children using maps

\begin{tabular}{|l|c|c|c|c|c|c|}
\hline \multirow{2}{*}{ Reasons for using maps } & \multicolumn{2}{|c|}{ Map-users } & \multicolumn{2}{c|}{ Non-map-users } & \multicolumn{2}{c|}{ Total } \\
\cline { 2 - 7 } & No. & $\%$ & No. & $\%$ & No. & $\%$ \\
\hline For fun & 6 & 6 & 0 & 0 & 6 & 5 \\
\hline To do homework & 9 & 9 & 3 & 15 & 12 & 10 \\
\hline Just curiosity & 12 & 12 & 7 & 35 & 19 & 16 \\
\hline Want to know other places & 36 & 36 & 3 & 15 & 39 & 32.5 \\
\hline $\begin{array}{l}\text { Find unfamiliar } \\
\text { places/ways }\end{array}$ & 32 & 32 & 6 & 30 & 38 & 31.5 \\
\hline Just come across & 5 & 5 & 1 & 5 & 6 & 5 \\
\hline Total number of ticks & 100 & & 20 & & 120 & \\
\hline
\end{tabular}

Altogether 120 ticks were recorded in response to this question. It is interesting to note that the map-user group used maps in the outdoor areas to know a place or to find their way in unfamiliar places. On the other hand, the non-map-user group used maps without a very clearly defined purpose. They used maps more often out of curiosity. Nevertheless, this should not be viewed as a negative act, since curiosity is a good intrinsic drive to learn new things (Bartlett, 1989). If teachers can take these findings into consideration together with the concern about place- and way-finding, then both map-using and non-map-using children are likely to find maps useful and interesting in their school studies.

\section{Did pre-teenage children have any map materials at home?}

This question sought to find out whether pre-teenage children were exposed to map-related materials at home. It was believed that the availability of such map resources at home could provide a favourable initial starting point to enable them to become familiar with maps before they actually learned them formally in school. Table 11 summarises the map resources available in these pre-teenage children' homes.

There were altogether 130 ticks recorded. Eighty per cent of the ticks were made by the map-user groups while $20 \%$ were made by the non-map-user group. Looked at with the $21 \%$ of non-map-user population (see Table 1 ), the $20 \%$ share of map resources and materials available at home with the non-map-users was logical, indicating that both map-users and non-map-users possessed some map 
Table 11 Map resources that were made available in the pre-teenage children's homes

\begin{tabular}{|l|c|c|c|c|c|c||}
\hline \multirow{2}{*}{ Map resources } & \multicolumn{3}{|c|}{ Map-users (66) } & Non-map-users (21) & \multicolumn{2}{c||}{ Total (87) } \\
\cline { 2 - 7 } & No. & $\%$ & No. & $\%$ & No. & $\%$ \\
\hline Wall map/map poster & 11 & 11 & 2 & 7.5 & 13 & 10 \\
\hline Globe model & 20 & 10 & 1 & 4 & 21 & 16 \\
\hline Atlas & 36 & 35 & 7 & 7 & 27 & 43 \\
\hline Pictorial map & 16 & 15 & 6 & 23 & 22 & 17 \\
\hline Map game & 20 & 19 & 9 & 34.5 & 29 & 22 \\
\hline Others & 1 & - & 1 & 4 & 2 & 2 \\
\hline Total number of ticks & 104 & $(80 \%)$ & 26 & $(20 \%)$ & 130 & $(100 \%)$ \\
\hline
\end{tabular}

resources at home. Hence, even if both groups of pre-teenage children recorded that they seldom used maps at home (see Table 9a), there was a chance for them to encounter maps or related materials (see Table 7) and then subsequently use such materials (see Table 8).

It was encouraging to see the availability of map resources at home, in particular atlases. It is not important to know whether these map resources were owned by the pre-teenage children themselves or belonged to the parents or other family members. As long as these map resources were accessible to the pre-teenage children at home, they could gradually build up a habit of using them whenever necessary. It is useful for geography teachers to consider how they can use these home resources to help pre-teenage children to become more acquainted with map use and to develop understanding in their map lessons. It was surprising that the second highest score was for map game materials. It is recognised that pre-teenage children learn more actively via a game situation (Marsh, 1994; Walford, 1996). The greater and more effective use of map game materials might possibly help pre-teenage children to learn and use some of the abstract map concepts under a simulated situation.

\section{Did pre-teenage children like reading maps?}

Although the 87 pre-teenage children were grouped into map-users and non-map-users, it is possible that not all the map-users actually like to use maps and that some non-map-users actually would like to use maps. When the children were asked whether they like reading maps, $53(63 \%)$ of them said they liked reading maps while $31(37 \%)$ of them said they did not like reading maps. Three pre-teenage children in the map-user group did not respond to this question. When this piece of information was combined with the information of map-users and non-map-users in Table 1, the resulting picture is summarised in Table 12.

Seventeen out of the total 63 responded map-users said that they did not like reading maps despite all the useful things that they had mentioned about maps in the earlier questions. Out of these 17 'dislike-map-users', there were more girls (14) than boys (3) who indicated their unfavourable attitude towards reading maps. On the other hand, the only two boys in the non-map-user group admitted their liking for reading maps. These numbers reveal the possible fact that there 
Table 12 Distribution between gender, map-user/non-map-user and like/dislike map pre-teenage children $(N=84$, with three map-user pre-teenage children not responding)

\begin{tabular}{|l|c|c|c|c|c|c|c|c|c|}
\hline \multirow{2}{*}{} & \multicolumn{4}{|c|}{ Like map } & \multicolumn{3}{c|}{ Dislike map } & \multicolumn{2}{c|}{ Total } \\
\cline { 3 - 11 } & & No. & Boys & Girls & No. & Boys & Girls & No. & $\%$ \\
\hline Map-users & 46 & 18 & 28 & 17 & 3 & 14 & 63 & 75 \\
\hline \multirow{2}{*}{ Non-map-users } & 7 & 2 & 5 & 14 & 0 & 14 & 21 & 25 \\
\cline { 2 - 11 } & Notal & 53 & 20 & 33 & 31 & 3 & 28 & 84 & 100 \\
\hline
\end{tabular}

are gender differences in terms of map learning which again agrees with the findings of Bramwell (1987) and Matthews (1986, 1992). However, that should form another focus for future investigation as the purpose of this study did not touch upon gender difference.

\section{How did pre-teenage children read maps?}

When the pre-teenage children were asked about how they read maps — on their own or together with some body else - the results in Table 13 reflect that, whether the pre-teenage children were map-users or non-map-users, they preferred, liked or were forced to read maps on their own. Seldom did they have the opportunity to read maps with other people, such as their brothers and sisters, parents or even with their peers at school. There may be scope for teachers to consider the use of peer-group learning to encourage idea exchange and interaction among pre-teenage children themselves so that they can learn or catch the abstract map concepts and practise mapping skills to enhance genuine map understanding more readily.

Table 13 Map reading companionship ( $N=82$, with five pre-teenage children not responding)

\begin{tabular}{|l|c|c|c|c|c|c|}
\hline \multirow{2}{*}{ Companionship } & \multicolumn{3}{|c|}{ Map-users } & \multicolumn{2}{c|}{ Non-map-users } & \multicolumn{2}{c|}{ Total } \\
\cline { 2 - 7 } & No. & $\%$ & No. & $\%$ & No. & $\%$ \\
\hline Alone & 35 & 55 & 8 & 44 & 43 & 52 \\
\hline With brother and/or sister & 9 & 14 & 3 & 17 & 12 & 15 \\
\hline With parents & 3 & 5 & 3 & 17 & 6 & 7 \\
\hline With classmates & 7 & 11 & 1 & 5 & 8 & 10 \\
\hline With friends & 10 & 15 & 3 & 17 & 13 & 16 \\
\hline Total & 64 & & 18 & & 82 & 100 \\
\hline
\end{tabular}

\section{Conclusion}

Despite the fact that pre-teenage children (age 11-12 years) do not begin to learn about maps formally until Secondary 1 in Hong Kong, they possess a reasonable amount of map experience. This study reveals major findings that the pre-teenage children see the main purpose of using maps as being to find unfamiliar places and to locate them in most daily situations. As a result, they like to deal with practical, real maps such as street maps and the MTR transport maps where the above mentioned practical map purpose can be achieved. Most 
of the pre-teenage children are aware of maps available in their surroundings. However, they may not be aware enough to notice or pay attention to reading them carefully. It is rather a matter of map awareness that puts the pre-teenage children into the two broad groups of map and non-map users. It also revealed that even those pre-teenage children who claimed to be non-map-users demonstrated some intuitive understanding of simple map concepts and elements.

Map resources available at home are particularly useful to stimulate children's interest in using maps more fully and effectively. If teachers can organise the map learning environment in such a way that pre-teenage children see the practical needs of utilising these map concepts, languages and skills in their daily life situations, they are likely to learn maps more readily. It is strongly suggested to Hong Kong geography teachers that real and practical maps of children's familiar environments should be used before hypothetical and unfamiliar ones, which pre-teenage children seldom see direct relevance in using. Pre-teenage children are more concerned about finding places on maps and they tend to be more aware of textual information in the process of way-finding. Yet, they also exhibit some understanding of symbolic representation on maps. It is believed that if familiar map environments are used and task-oriented map exercises are set, this will gradually help the pre-teenage children to get over the barrier of moving from textual to pictorial symbolic representation, from concrete to formal operational stage, and from concrete to abstract map understanding. Teachers should take into consideration all of these when planning the teaching of mapwork in Secondary 1 . Their pre-teenage children possess quite a lot of map knowledge, in the form of map types and map uses. It is important for teachers to use the prior knowledge and vernacular experience of pre-teenage children to develop their interest and ability in mapwork to fulfil the purpose of cartographic communication. This is summarised by Burden (1987) and Gerber (1993) as the understanding of spatial features and information about reality between map makers and map users.

\section{Correspondence}

Any correspondence should be directed to Tammy Kwan, Department of Curriculum Studies, The University of Hong Kong, Pokfulam Road, Hong Kong (tylkwan@hkucc.hku.hk).

\section{Notes}

1. The Hong Kong junior secondary level is Secondary 1 to 3 , which is equivalent to Years 8 to 10 in Queensland, Australia, and is equivalent to Key Stage 3 of the National Curriculum in the UK.

2. 'New middle class' refers to those professional, administrative, and managerial employees working in various sectors of the Hong Kong Economy (Cheng, 1997:212).

\section{Appendix 1}

\section{Pre-teenage children's perception of maps}

(1) How much do pre-teenage children experience about maps before formal mapwork begins? 
- Have the pre-teenage children used maps before?

- If the pre-teenage children have used maps before, what did they use maps for?

(2) What do pre-teenage children understand maps to be?

- Which graphic is a map? Why do the pre-teenage children think it is a map?

- What are the things (items) that need to be included on a map?

- Which things (items) on a map do pre-teenage children believe they know the meanings of?

(3) What are the pre-teenage children's perceptions on the purposes of maps?

- Ranking of map purposes

(4) How many different types of maps do pre-teenage children know?

- What are the different types of maps?

- What kind of map do pre-teenage children think they might and might not use most often?

\section{Pre-teenage children's experiences with maps}

(5) What are the pre-teenage children's personal experiences with maps?

- How often did pre-teenage children encounter maps?

- How often did pre-teenage children use maps?

- Where did pre-teenage children use maps most often?

- Why did pre-teenage children use maps?

- Did pre-teenage children have any map materials at home?

- Did pre-teenage children like reading maps?

- How did pre-teenage children read maps?

\section{References}

Balchin, W.G.V. (1985) Graphicacy comes of age. Teaching Geography 11 (1), 8-9.

Bartlett, L. (1989) Look into my mind: Qualitative inquiry in teaching geography. In J. Fien, R. Gerber and P. Wilson (eds) The Geography Teacher's Guide to the Classroom (pp. 141-152). MacMillan.

Bartlett, L. and Cox, B. (1982) Learning to Teach Geography. Brisbane: Wiley.

Bartz, B.S. (1970) Maps in the classroom. Journal of Geography 69 (1), 18-24.

Boardman, D. (1989) The development of graphicacy: Children's understanding of maps. Geography 74 (4), 321-331.

Bramwell, J. (1987) Pupils' attitudes towards geography in lower school: An investigation into gender differences. Geography 72 (1), 36-48.

Burden, P.J. (1987) It's All Said with the Graphics. Brisbane: The Australian Key Centre in Land Information Studies.

Cheng, J.Y.S. (ed.) (1997) The Other Hong Kong Report: 1997. Hong Kong: The Chinese University Press.

Dale, P.F. (1971) Children's relations to maps and aerial photography. AREA 3 (3), 170-177.

Freundschuh, S. (1990) Can young children use maps to navigate? Cartographica 27,54-66.

Gerber, R.V. (1981) Young children's understanding of the elements of maps. Teaching Geography 6 (3), 128-133.

Gerber, R.V. (1982) An international study of children's perception and understanding of type used on atlas maps. The Cartographic Journal 19 (2), 115-119.

Gerber, R.V. (1993) Map design for children. The Cartographic Journal 30, 154-158. 
Keates, J.S. (1982) Understanding Maps. London: Longman.

Kwan, T. (1994) Teachers' perceptual understanding of mapwork and their style of mapwork teaching at Forms 1-3 in Hong Kong. Asian Geographer 36, 94-103.

Kwan, T. (1995) Hong Kong children's understanding and experience of mapwork tasks. Unpublished doctoral thesis, Queensland University of Technology.

Kwan, T. (1996) Understanding children's intuitive experience and their familiar environment in teaching of maps. In R. Gerber and J. Lidstone (eds) Developments and Directions in Geographical Education (pp. 197-224). Clevedon: Channel View Publications.

Liben, L.S. and Downs, R.M. (1989) Understanding maps as symbols: The development of map concepts in children. Advances in Child Development and Behaviour 22, 145-201.

Marsh, C. (1994) Simulation games. In C. Marsh (ed.) Teaching Studies of Society and Environment (pp. 213-240). Sydney: Prentice Hall.

Matthews, H. (1984a) Cognitive mapping abilities of young boys and girls. Geography 69, 327-336.

Matthews, H. (1984b) Environmental cognition of young children: Images of journey to school and home area. Transactions, Institute of British Geographers 9 (1), 89-105.

Matthews, H. (1986) Gender, graphicacy and geography. Educational Review 38 (3), 259-271.

Matthews, H. (1992) Making Sense of Places: Children's Understanding of Large Scale Environments. Hemel Hempstead: Harvester Wheatsheaf.

Ottosson, T. (1987) Map-reading and wayfinding. Goteborg Studies in Educational Science, 65.

Piaget, J. (1929) The Child's Conception of the World. London: Routledge.

Piaget, J. and Inhelder, B. (1956) The Child's Conception of Space. London: Routledge.

Rushdoony, H.A. (1969) A child's ability to read maps: Summary of the research. Journal of Geography 7, 213-222.

Satterly, D.J. (1964) Skills and concepts involved in map drawing and map interpretation. In J. Bale et al. (eds) (1973) Perspectives in Geographical Education. Edinburgh: Oliver and Boyd.

Spencer, C., Blades, M. and Morsley, K. (1989) The Child in the Physical Environment. Chichester: Wiley and Son.

Stimpson, P.G. (1987) Improving the graphical ability of children and the teaching of mapwork. The Geography Bulletin 17, 60-66. Department of Education, Hong Kong.

Tierney, G. (1985) A study of the development of spatial cognition and ability in primary and secondary schools. Unpublished MA dissertation, University of London.

Walford, R. (1996) The simplicity of simulation. In P. Bailey and P. Fox (eds) Geography Teachers' Handbook (pp. 139-145). The Geographical Association: Sheffield.

Walker, R.J. (1980) The map using abilities of 5-9 year old children. Geographical Education 3, 545-554.

Wilson, P.S. (1980) The map-reasoning development of pupils in years 3, 5 and 7 as revealed in free recall sketch maps. Unpublished PhD thesis, Ohio State University. 